\title{
STUDI LITERATURE: CARA MENURUNKAN HIPERTENSI DENGAN LATIHAN FISIK
}

\author{
Nurhidayah Amir ${ }^{1 *}$, Rifki Sakinah Nompo ${ }^{2}$, Angela L Thome ${ }^{3}$, Yuliana Done ${ }^{4}$, \\ Viertianingsih Patungo ${ }^{5}$, Fathia Fakhri Inayati Said ${ }^{6}$ \\ 1,2,3,5,6 STIKES Jayapura \\ ${ }^{4}$ Puskesmas Ilu Puncak Jaya \\ Email Korespondensi : nurhidayahamir07@gmail.com \\ Disubmit: 22 Januari 2022 Diterima: 23 Januari 2022 Diterbitkan: 01 Februari 2022 \\ DOI: https://doi.org/10.33024/mnj.v5i2.5888
}

\section{ABSTRACT: LITERATURE STUDY: HOW TO REDUCE HYPERTENSION WITH PHYSICAL EXERCISE}

Background: Hypertension is high blood pressure which is divided into three levels, namely pre-hypertension, first-degree hypertension and second-degree hypertension. Hypertension is also dubbed the silent killer because most of the causes are unknown, where the symptoms that arise vary in each individual and these symptoms are similar to the symptoms of other diseases. Symptoms of hypertension include: heaviness in the neck, headaches, heart palpitations, blurred vision, ringing in the ears, fatigue, vertigo, and nosebleeds.

Objective: This study aims to determine physical exercise in lowering blood pressure in hypertensive patients.

Methods: This research is a literature study research. The data in this study were obtained from three databases, namely Google Scholar, Garuda and PubMed with the keywords "physical exercise, physical exercise, high blood pressure, high blood pressure, hypertension, hypertension". The study used the PICOS method, by reviewing the journals used.

Results: Based on the results of this study, it was found that there are various kinds of physical exercise including: aerobic exercise, walking (walking), cardio exercise, elderly exercise, home-base exercise training, isometric resistance training. In addition, the duration of each physical exercise depends on the patient's condition, age, and the type of physical exercise performed.

Conclusion: Each physical exercise used is not the same from one individual to another, therefore the patient can choose which one is the most comfortable and can be done every time.

Keywords: Hypertension, Physical Exercise 


\section{INTISARI: STUDI LITERATURE: CARA MENURUNKAN HIPERTENSI DENGAN LATIHAN FISIK}

Latar Belakang: Hipertensi merupakan tekanan darah tinggi yang dibagi atas tiga tingkatan yaitu pre-hipertensi, hipertensi derajat satu dan hipertensi derajat dua. Hipertensi dijuluki juga sebagai silent killer karena hampir sebagian besar tidak diketahui penyebab terjadinya, dimana gejala yang timbul bervariasi pada tiap individu dan gejala ini mirip dengan gejala penyakit lainnya. Gejala hipertensi ini seperti: rasa berat ditengkuk, sakit kepala, jantung berdebar-debar, penglihatan kabur, telinga berdenging, mudah lelah, vertigo, dan mimisan.

Tujuan: Penelitian ini bertujuan untuk mengetahui latihan fisik dalam menurunkan tekanan darah pasien hipertensi.

Metode: Penelitian ini adalah penelitian studi literature . Data pada penelitian ini didapatkan dari tiga data base yaitu Google Cendekia, Garuda dan PubMed dengan kata kunci "latihan fisik, physical exercise, tekanan darah tinggi, high blood pressure, hipertensi, hypertension”. Penelitian menggunakan metode PICOS, dengan melakukan review pada jurnal-jurnal yang digunakan.

Hasil: Berdasarkan hasil penelitian ini, didapatkan bahwa terdapat berbagai macam latihan fisik diantaranya: senam aerobik, walking (berjalan), latihan kardio, senam lansia, home-base exercise training, latihan resistensi isometrik. Selain itu durasi tiap latihan fisik tergantung pada kondisi pasien, usia, dan jenis latihan fisik yang dilakukan.

Kesimpulan: Setiap latihan fisik yang digunakan tidak sama antara individu satu dengan lainnya, oleh sebab itu pasien dapat memilih mana yang paling nyaman dan dapat dilakukan tiap waktunya.

Kata kunci : Hipertensi, Latihan Fisik

\section{PENDAHULUAN}

Hipertensi atau tekanan darah tinggi merupakan salah satu contoh penyakit degeneratif. Penyakit darah tinggi atau hipertensi adalah suatu peningkatan abnormal tekanan darah dalam pembuluh arteri secara terus menerus lebih dari suatu periode. Hipertensi didefinisikan sebagai peningkatan tekanan darah sistolik, sedikitnya $140 \mathrm{mmHg}$ atau tekanan diastolik sedikitnya $90 \mathrm{mmHg}$ (Saputra \& Daud, 2020).

Prevalensi hipertensi di dunia diperkirakan sebesar 1 milyar jiwa dan hampir 7,1 juta kematian setiap tahunnya akibat hipertensi, atau sekitar $13 \%$ dari total kematian dan diperkirakan pada tahun 2025 akan ada sebanyak 1,56 milyar dewasa yang akan menderita hipertensi
(Hernawan \& Rosyid, 2017; Sarastuti \& Widyantoro, 2018).

Di Indonesia, kasus hipertensi mencapai $8,36 \%$ dari nilai total populasi keseluruhan (658.201), dengan sebaran di tiap provinsi. Lima provinsi tertinggi hipertensi berdasarkan diagnosis terdapat di Provinsi Sulawesi Utara sebesar 13,21\%, Daerah Istimewa Jogyakarta sebesar 10,68\%, Provinsi Kalimantan Timur 10,57\%, Kalimantan Utara $10,46 \%$ dan Jakarta 10,17\% (Rikesdas, 2018).

Gejala-gejala yang dirasakan penderita hipertensi adalah pusing, mudah marah, telinga berdengung, sukar tidur, sesak nafas, rasa berat ditengkuk, mudah lelah, mata berkunang-kunang, mimisan, muka pucat, dan suhu tubuh rendah. Penyebab hipertensi dibagi menjadi 
dua golongan, yaitu: (1) hipertensi esensial/ primer, yaitu hipertensi yang tidak diketahui penyebabnya, dan ada kemungkinan karena faktor keturunan atau genetik (90\%); dan (2) hipertensi sekunder, yaitu hipertensi yang merupakan akibat dari adanya penyakit lain seperti kelainan pembuluh ginjal dan gangguan kelenjar tiroid (10\%) (Saputra \& Daud, 2020).

Hipertensi erat kaitannya dengan gaya hidup tidak sehat seperti konsumsi makanan tinggi garam, tidak mengonsumsi cukup buah-buahan dan sayur-sayuran, konsumsi alkohol berlebih, kurangnya olahraga atau latihan fisik, manajemen stress yang buruk, merokok, dan kurangnya istirahat (WHO, 2018; Saputra \& Daud, 2020).

Aktivitas fisik adalah setiap gerakan tubuh (skeletal muscle) yang meningkatkan pengeluaran tenaga dan energi (pembakaran kalori). Sedangkan latihan fisik, merupakan bagian dari aktivitas fisik yang terencana, teratur, terukur, dan terarah untuk mencapai suatu kebugaran fisik. Latihan fisik yang dimaksud adalah melakukakan kegiatan sehari-hari seperti berjalan, menyapu halaman, membersihkan rumah. Namun untuk mencapai tujuan kebugaran latihan fisik perlu dilakukan secara teratur dan terukur sebagai salah satu upaya non-farmakologis pada penyakit hipertensi (Sarastuti \& Widyantoro, 2018).

Aktivitas fisik teratur, kebugaran dan latihan fisik sangat penting untuk penanganan penyakit hipertensi. WHO (World Health Organization) mendefinisikan latihan fisik sebagai aktivitas fisik yang direncanakan, terstruktur, berulang, dan bertujuan untuk memperbaiki atau mempertahankan satu atau lebih komponen kebugaran fisik (WHO, 2018).

Terdapat penelitian yang menunjukkan bahwa melakukan latihan secara teratur (latihan fisik aerobik selama 30-45 menit/hari) diketahui sangat efektif dalam mengurangi risiko relatif hipertensi hingga mencapai 19\% hingga $30 \%$. Begitu juga halnya dengan kebugaran kardio-respirasi yang rendah pada usia paruh baya diduga meningkatkan risiko hipertensi sebesar 50\% (Adamas, 2019).

Penelitian yang sama juga dilakukan oleh Izhar (2017), dimana hasil penelitian tersebut menunjukkan adanya pengaruh senam lansia terhadap tekanan darah sistole lansia, sama halnya dengan hasil analisis bivariate tekanan darah diastole menunjukkan adanya pengaruh tekanan diastole sebelum dan sesudah senam lansia. Begitu juga dengan penelitian yang dilakukan oleh Sumartini, Zulkifli \& Adhitya (2019) yang menunjukkan adanya pengaruh senam hipertensi lansia terhadap tekanan darah lansia yang didiagnosis hipertensi.

Berdasarkan uraian latar belakang diatas peneliti tertarik lebih dalam untuk meneliti terkait latihan fisik dalam menurunkan tekanan darah pasien hipertensi.

\section{METODOLOGI PENELITIAN}

Penelitian ini adalah penelitian literature review. Data pada penelitian ini didapatkan dari tiga data base yaitu Google Cendekia, Garuda dan PubMed dengan kata kunci "latihan fisik, physical exercise, tekanan darah tinggi, high blood pressure, hipertensi, hypertension". Jumlah jurnal yang digunakan dari Google Cendekia sebanyak dua belas jurnal, Garuda sebanyak satu jurnal dan PubMed sebanyak enam junal. Penelitian ini menggunakan metode PICOS dan melakukan review pada jurnal-jurnal yang digunakan serta rentang tahun jurnal 2017-2021. 
HASIL DAN PEMBAHASAN

Tabel 1 Daftar Artikel Hasil Pencarian

\begin{tabular}{|c|c|c|c|c|c|c|}
\hline No & Author & Tahun & Judul & $\begin{array}{l}\text { Metode (Metode, sampel, } \\
\text { variabel, intervensi, } \\
\text { analisis) }\end{array}$ & Hasil Penelitian & Database \\
\hline 1 & Arija., et al & 2018 & $\begin{array}{l}\text { Physical activity, } \\
\text { cardiovascular } \\
\text { health, quality of life } \\
\text { and blood pressure } \\
\text { control in } \\
\text { hypertensive } \\
\text { subjects: randomized } \\
\text { clinical trial }\end{array}$ & $\begin{array}{l}\text { Menggunakan metode } \\
\text { randomized clinical trial } \\
\text { dengan program intervensi } \\
\text { PA (Physical Activity) selama } \\
9 \text { bulan durasi, terdiri dari } \\
\text { kelompok jalan kaki } 120 \\
\text { menit/minggu, diawasi, dan } \\
\text { dengan kegiatan sosial } \\
\text { budaya. }\end{array}$ & $\begin{array}{l}\text { Program intervensi PA ini } \\
\text { meningkatkan kesehatan } \\
\text { kardiovaskular dan HRQL, } \\
\text { dan mendukung kontrol } \\
\text { tekanan darah dalam } \\
\text { pengguna layanan primer } \\
\text { dengan hipertensi. }\end{array}$ & PubMed \\
\hline 2 & $\begin{array}{c}\text { Zhang, S, M. } \\
\text { L., et al }\end{array}$ & 2020 & $\begin{array}{l}\text { Blood pressure } \\
\text { control in } \\
\text { hypertensive patients } \\
\text { and its relation with } \\
\text { exerciser and } \\
\text { exercise-related } \\
\text { behaviors }\end{array}$ & $\begin{array}{lr}\text { Menggunakan } & \text { metode } \\
\text { penelitian kuantitatif } & \text { an } \\
\text { deskriptif, dengan jumlah } \\
\text { sampel 598. Menggunakan } \\
\text { uji multivariasi analisis } \\
\text { regresi logistik }\end{array}$ & $\begin{array}{l}\text { Ada hubungan antara } \\
\text { perilaku terkait olahraga } \\
\text { dan kontrol tekanan darah: } \\
\text { berjalan }(\mathrm{OR}=0,189,95 \% \mathrm{Cl}: \\
0,065-0,551), 60 \text { hingga } 120 \\
\text { menit/hari waktu latihan } \\
(\mathrm{OR}=0.317,95 \% \mathrm{Cl} \text { : } 0.118- \\
0.856) \text { Jenis Kelamin } \\
(\mathrm{OR}=2.248,95 \% \mathrm{Cl}: 1.279- \\
3.954), \quad 0 \text { keyakinan } \\
\text { kesehatan }(\mathrm{OR}=0.016,95 \% \\
\mathrm{Cl} \quad 0,004-0,059), \quad \text { dan } \\
\text { kehadiran anggota keluarga } \\
\text { saat berolahraga }(\mathrm{OR}=0,048 \text {, } \\
95 \% \quad \mathrm{Cl} \quad 0,025-0,094) \\
\text { merupakan faktor yang } \\
\text { signifikan prediksi olahraga } \\
\text { teratur pada pasien } \\
\text { hipertensi. }\end{array}$ & PubMed \\
\hline 3 & $\begin{array}{l}\text { Nascimento, } \\
\text { L. S., et al }\end{array}$ & 2017 & $\begin{array}{l}\text { Acute and chronic } \\
\text { effects of aerobic } \\
\text { exercise on blood } \\
\text { pressure in resistant } \\
\text { hypertension: study } \\
\text { protocol for a } \\
\text { randomized } \\
\text { controlled trial }\end{array}$ & $\begin{array}{lr}\text { Menggunakan } & \text { metode } \\
\text { randomized clinical trial, } \\
\text { desain } \\
\text { eksperimental penelitian } \\
\text { sampel berjumlah } 48 \text { orang. } \\
\text { Intervensi menggunakan sesi } \\
\text { latihan aerobik (intensitas } \\
\text { ringan, sedang dan tinggi) }\end{array}$ & $\begin{array}{l}\text { Pentingnya olahraga untuk } \\
\text { hipertensi telah diketahui } \\
\text { selama beberapa dekade, } \\
\text { tetapi sedikit yang diketahui } \\
\text { tentang efek pada pasien } \\
\text { dengan hipertensi resisten. } \\
\text { Studi ini akan membantu } \\
\text { untuk memahami apakah } \\
\text { latihan aerobik yang } \\
\text { berbeda intensitas dapat } \\
\text { menyebabkan respons yang } \\
\text { berbeda, serta dengan } \\
\text { mekanisme apa penyesuaian } \\
\text { tingkat tekanan darah } \\
\text { mungkin terjadi. }\end{array}$ & PubMed \\
\hline 4 & $\begin{array}{l}\text { Diaz, K. M., } \\
\text { et al }\end{array}$ & 2017 & $\begin{array}{l}\text { Physical Activity and } \\
\text { Incident } \\
\text { Hypertension in } \\
\text { African Americans: } \\
\text { The Jackson Heart } \\
\text { Study }\end{array}$ & $\begin{array}{l}\text { Desain } \\
\text { menggunakan retro survey } \\
\text { yang mengambil sampel } \\
\text { sebesar } 1.311 \text { dari tahun } \\
(2000-2022) . \text { Uji satatistik } \\
\text { menggunakan persentasse }\end{array}$ & $\begin{array}{l}\text { MVPA (moderate-vigorous } \\
\text { physical activity), teratur } \\
\text { atau aktivitas fisik yang } \\
\text { berhubungan dengan } \\
\text { olahraga dapat mengurangi } \\
\text { risiko terkena hipertensi } \\
\text { pada orang Afrika-Amerika. }\end{array}$ & PubMed \\
\hline 5 & $\begin{array}{l}\text { Pedralli, M. } \\
\text { L., et al }\end{array}$ & 2020 & $\begin{array}{lr}\text { Different } & \text { Exercise } \\
\text { training Modalities } \\
\text { produce similar } \\
\text { Endothelial function } \\
\text { improvements in } \\
\text { individuals with } \\
\text { prehypertension or } \\
\text { hypertension: a } \\
\text { randomized Clinical } \\
\text { trial exercise, } \\
\text { endothelium and } \\
\text { blood pressure }\end{array}$ & $\begin{array}{l}\text { Penelitian kuantitatif } \\
\text { eksperimental dengan } \\
\text { sampel pre hipertensi dan } \\
\text { hipertensi sebanyak } 42 \text { yang } \\
\text { dibagi dalam tiga group kecil } \\
14 \text { orang perkelompok untuk } \\
\text { dilakukan latihan fisik } \\
\text { latihan senam aerobik, } \\
\text { pelatihan ketahanan, } \\
\text { gabungan aerobic dan } \\
\text { latihan ketahanan }\end{array}$ & $\begin{array}{l}\text { Terapi modalitas terkait } \\
\text { pelatihan olahraga sama } \\
\text { efektifnya } \\
\text { meningkatkan dalam } \\
\text { endotel yang berdampak } \\
\text { pada } \\
\text { tekanan darah pasien rawat } \\
\text { jalan tampaknya bervariasi } \\
\text { pada individu dengan pre- } \\
\text { hipertensi atau hipertensi. }\end{array}$ & PubMed \\
\hline 6 & $\begin{array}{c}\text { Babu, A. S., } \\
\text { et al }\end{array}$ & 2019 & 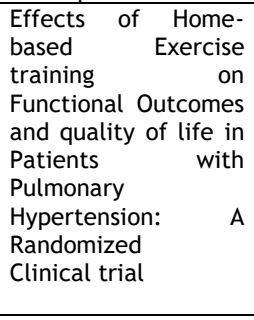 & 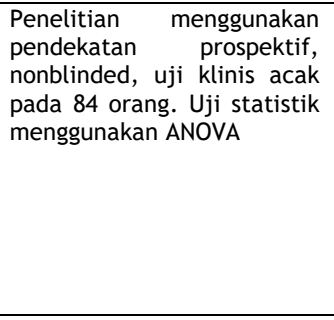 & $\begin{array}{l}\text { HBET (home-based exercise } \\
\text { training) meningkatkan } \\
\text { 6MWD (6-min walk distance) } \\
\text { masing-masing sebesar } 48,5 \\
m \text { dan } 13 \mathrm{~m} \text { pada kelompok } \\
\text { eksperimen dan control ( } \mathrm{p}< \\
0,001) \text {. QoL (quality of life) } \\
\text { menunjukkan peningkatan } \\
\text { statistik setelah HBET } \\
\text { antara kelompok untuk fisik } \\
\text { dan komponen mental dan }\end{array}$ & PubMed \\
\hline
\end{tabular}




\begin{tabular}{|c|c|c|c|c|c|c|}
\hline & & & & & $\begin{array}{l}\text { untuk berbagai subdomain } \\
\text { (kecuali nyeri tubuh). } \\
\text { Selanjutnya, FC (functional } \\
\text { class) ditingkatkan dengan } \\
\text { satu kelas dengan HBET ( } p \\
<0,001 \text { ). }\end{array}$ & \\
\hline 7 & $\begin{array}{l}\text { Saputra, F., } \\
\text { \& Daud, T }\end{array}$ & 2020 & $\begin{array}{lr}\text { Pengaruh } & \text { Latihan } \\
\text { Fisik } & \text { Terhadap } \\
\text { Penurunan hipertensi } \\
\text { Pada lansia di } \\
\text { poswindu } \quad \text { wilayah } \\
\text { kerja } \quad \text { puskesmas } \\
\text { Bintuhan } & \text { Kabupaten } \\
\text { Kaur } & \end{array}$ & $\begin{array}{l}\text { Rancangan penelitian Pre- } \\
\text { Experimental Design (The } \\
\text { One Group Pre Tes-Post Test } \\
\text { Design). Jumlah sampel } 15 \\
\text { orang. Uji menggunakan } \\
\text { rata-rata dan one-way anova }\end{array}$ & $\begin{array}{l}\text { Ada rata-rata perbedaan } \\
\text { penurunan hipertensi pada } \\
\text { lansia sebelum dan setelah } \\
\text { melakukan latihan fisik di } \\
\text { Poswindu wilayah kerja } \\
\text { Puskesmas Bintuhan } \\
\text { Kabupaten Kaur Tahun } 2019 \\
\text { yaitu sistole } 11,44000 \mathrm{mmHg} \\
\text { dan diastole } 6,6600 \mathrm{mmHg} \\
\text { dengan nilai } \mathrm{P}=0,000\end{array}$ & Garuda \\
\hline 8 & $\begin{array}{l}\text { Sianipar, S. } \\
\text { S., et al }\end{array}$ & 2018 & $\begin{array}{lr}\text { Pengaruh } & \text { Senam } \\
\text { Hipertensi } & \text { Terhadap } \\
\text { Tekanan } & \text { Darah } \\
\text { Penderita } & \text { Hipertensi } \\
\text { Di Puskesmas Kayon } \\
\text { Kota Palangka Raya }\end{array}$ & $\begin{array}{l}\text { Desain penelitian yang } \\
\text { digunakan adalah pra } \\
\text { eksperimental dengan } \\
\text { rancangan penelitian pra- } \\
\text { pasca tes dalam suatu } \\
\text { kelompok (One-group pra- } \\
\text { post test design). Sampel } 39 \\
\text { orang, uji statistik yang } \\
\text { digunakan Wilcoxon Signed } \\
\text { Rank Test }\end{array}$ & $\begin{array}{l}\text { Didapatkan nilai } \mathrm{p} \text { value } \\
\text { adalah } 0,000<\mathrm{a} 0,05 \text { yang } \\
\text { berarti terdapat pengaruh } \\
\text { senam hipertensi terhadap } \\
\text { tekanan darah pada } \\
\text { penderita hipertensi di } \\
\text { Puskesmas Kayon Kota } \\
\text { Palangka Raya. }\end{array}$ & $\begin{array}{l}\text { Google } \\
\text { Cendikia }\end{array}$ \\
\hline 9 & $\begin{array}{l}\text { Safitri, W., } \\
\text { \& Adtuti, H. } \\
\text { P }\end{array}$ & 2017 & 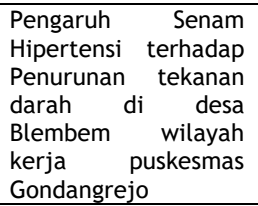 & $\begin{array}{l}\text { Rancangan penelitian yang } \\
\text { digunakan adalah one group } \\
\text { pre-test dan post-test } \\
\text { design. Jumlah sample } \\
\text { 40orang. Menggunakan uji } \\
\text { wilcoxon }\end{array}$ & $\begin{array}{lr}\text { Ada pengaruh } & \text { senam } \\
\text { hipertensi } & \text { terhadap } \\
\text { penurunan tekanan darah di } \\
\text { Desa Blembem Wilayah } \\
\text { Kerjar Puskesmas } \\
\text { Gondangrejo dengan p value } \\
0,000 .\end{array}$ & $\begin{array}{l}\text { Google } \\
\text { Cendikia }\end{array}$ \\
\hline 10 & $\begin{array}{c}\text { Anwari, M., } \\
\text { et al }\end{array}$ & 2018 & $\begin{array}{l}\text { Pengaruh Senam Anti } \\
\text { Hipertensi Lansia } \\
\text { Terhadap Penurunan } \\
\text { Tekanan Darah Lansia } \\
\text { Di Desa Kemuningsari } \\
\text { Lor Kecamatan Panti } \\
\text { Kabupaten Jember }\end{array}$ & $\begin{array}{l}\text { Penelitian } \\
\text { dengan }\end{array} \begin{array}{l}\text { kuantitatif } \\
\text { rancangan } \\
\text { preexperiment design One } \\
\text { Group Pre-test-post test. } \\
\text { Jumlah sampel } 16 \text { orang. Uji } \\
\text { statistik yang digunakan } \\
\text { Wilcoxon Signed Rank Test }\end{array}$ & $\begin{array}{l}\text { Hasil dari penelitian ini } \\
\text { adalah tekanan darah } \\
\text { sebelum pemberian } \\
\text { intervensi sebagian besar } \\
\text { adalah prehypertension } \\
(87,5 \%) \text { tekanan darah } \\
\text { setelah } \\
\text { intervensi senam hipertensi } \\
\text { sebagian besar adalah } \\
\text { normal }(87,5 \%), \quad \text { dan } \\
\text { terdapat pengaruh senam } \\
\text { anti hipertensi terhadap } \\
\text { tekanan darah lansia di Desa } \\
\text { Kemuningsari } \\
\text { Kecamatan Panti Kabupaten } \\
\text { Jember (p-value }=0,001)\end{array}$ & $\begin{array}{l}\text { Google } \\
\text { Cendikia }\end{array}$ \\
\hline 11 & $\begin{array}{l}\text { Ratnawati, } \\
\text { D., \& } \\
\text { Choirillaily, } \\
\text { S }\end{array}$ & 2020 & $\begin{array}{l}\text { Latihan } \\
\text { Menggenggam Alat } \\
\text { Handgrip } \\
\text { Menurunkan Tekanan } \\
\text { Darah Pada Penderita } \\
\text { Hipertensi }\end{array}$ & $\begin{array}{l}\text { Penelitian menggunakan } \\
\text { desain penelitian quasi } \\
\text { experimental pre dan post } \\
\text { test dengan satu kelompok } \\
\text { intervensi. Jumlah sampel } \\
16 \text { orang, dengan uji } \\
\text { statistik menggunakan } \\
\text { Wilcoxon signed ranks }\end{array}$ & $\begin{array}{l}\text { Hasil penelitian didapatkan } \\
\text { latihan menggenggam alat } \\
\text { handgrip dapat menurunkan } \\
\text { tekanan darah sistolik dan } \\
\text { diastolik }\end{array}$ & $\begin{array}{l}\text { Google } \\
\text { Cendikia }\end{array}$ \\
\hline 12 & $\begin{array}{l}\text { Rahmiati, } \\
\text { C., \& } \\
\text { ZurijahT. I }\end{array}$ & 2020 & $\begin{array}{lr}\text { Pengaruh } & \text { Senam } \\
\text { Lansia } & \text { terhadap } \\
\text { Tekanan } & \text { Darah Pada } \\
\text { Lansia } & \text { Dengan } \\
\text { Hipertensi } & \\
\end{array}$ & $\begin{array}{l}\text { Penelitian ini merupakan } \\
\text { jenis penelitian eksperimen } \\
\text { semu (quasi experiment) } \\
\text { dengan rancangan pre and } \\
\text { post test without control. } \\
\text { Jumlah sampel } 33 \text {. Uji } \\
\text { statistik yang digunakan Uji } \\
\text { t-test dengan tiga kategori } \\
\text { yaitu hipertensi ringan, } \\
\text { sedang dan berat }\end{array}$ & $\begin{array}{l}\text { Terdapat perbedaan } \\
\text { tekanan darah pada lansia } \\
\text { sebelum dan sesudah senam } \\
\text { lansia dengan p-value } 0,000 \text {, }\end{array}$ & $\begin{array}{l}\text { Google } \\
\text { Cendikia }\end{array}$ \\
\hline 13 & $\begin{array}{l}\text { Hernawan, } \\
\text { T., \& } \\
\text { Rosyid, F. N }\end{array}$ & 2017 & 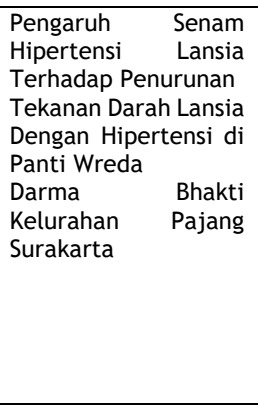 & $\begin{array}{l}\text { Penelitian menggunakan } \\
\text { design kuantitatif dengan } \\
\text { pendekatan preexperiment } \\
\text { design One Group Pre-test } \\
\text { post test. Pengumpulan data } \\
\text { menggunakan } \\
\text { Sphygmomanometer air } \\
\text { raksa, julah sampel } 28 \\
\text { orang, dan uji statistik } \\
\text { menggunakan Wilcoxon } \\
\text { Signed Rank Test. }\end{array}$ & 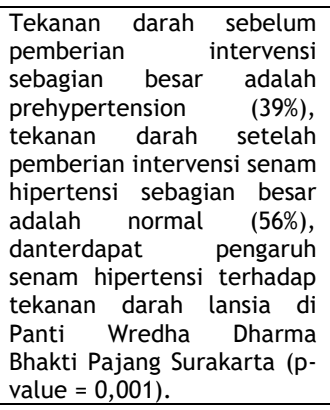 & $\begin{array}{l}\text { Google } \\
\text { Cendikia }\end{array}$ \\
\hline
\end{tabular}




\begin{tabular}{|c|c|c|c|c|c|c|}
\hline 14 & $\begin{array}{l}\text { Larasiska, } \\
\text { A., \& HN, } \\
\text { W. P }\end{array}$ & 2017 & $\begin{array}{l}\text { Menurunkan Tekanan } \\
\text { Darah } \\
\text { dengan Cara Mudah } \\
\text { pada Lansia }\end{array}$ & $\begin{array}{l}\text { Metode Penelitian ini } \\
\text { menggunakan desain } \\
\text { penelitian eksperimen } \\
\text { semu, menggunakan } \\
\text { rancangan time series } \\
\text { design, dilakukan pre testt } \\
\text { dan post-test sebanyak dua } \\
\text { kali perlakuan. Sampel } \\
\text { dalam penelitian berjumlah } \\
12 \text { diambil menggunakan } \\
\text { tehnik purpsive sampling. } \\
\text { uji statistik menggunakan } \\
\text { Wilcoxon. }\end{array}$ & $\begin{array}{l}\text { Hasil untuk systole dengan } \\
\text { nilai } z \text { hitung } \\
=-2,271 \text { dan } p \text { value sebesar } \\
0,023=a<0,05 \text {. Selain itu } \\
\text { hasil untuk diastole dengan } \\
\text { nilai } z \text { hitung }=-2,530 \text { dan } p \\
\text { value sebesar } 0,011=a< \\
0,05 \text { yang artinya ada } \\
\text { pengaruh antara jalan kaki } \\
\text { terhadap tekanan darah } \\
\text { pada lansia hipertensi. }\end{array}$ & $\begin{array}{l}\text { Google } \\
\text { Cendikia }\end{array}$ \\
\hline 15 & $\begin{array}{l}\text { Tulak, G. T., } \\
\text { \& Umar, M }\end{array}$ & 2017 & $\begin{array}{lr}\text { Pengaruh } & \text { Senam } \\
\text { Lansia } & \text { Terhadap } \\
\text { Penurunan } & \text { Tekanan } \\
\text { Darah } & \text { Lansia } \\
\text { Penderita } & \text { Hipertensi } \\
\text { Di Puskesmas Wara } \\
\text { Palopo }\end{array}$ & $\begin{array}{l}\text { Penelitian ini bersifat } \\
\text { kuantitatif pre eksperimen } \\
\text { dengan rancangan pretest- } \\
\text { postest design. Data } \\
\text { dikumpulkan dengan lembar } \\
\text { observasi dengan jumlah } \\
\text { sampel } 36 \text { orang yang } \\
\text { diperoleh dengan cara total } \\
\text { sampling. Diuji dengan } \\
\text { menggunakan paired- } \\
\text { samples test }\end{array}$ & $\begin{array}{l}\text { Terdapat pengaruh senam } \\
\text { lansia terhadap tekanan } \\
\text { darah sistolik, dengan nilai } \\
\text { p }<0,05 \text { yaitu pertemuan } \\
\text { diperoleh nilai } p=0,000\end{array}$ & $\begin{array}{l}\text { Google } \\
\text { Cendikia }\end{array}$ \\
\hline 16 & $\begin{array}{l}\text { Yanti, M., } \\
\text { dkk }\end{array}$ & 2021 & $\begin{array}{lr}\text { Senam } & \text { Lansia } \\
\text { Terhadap } & \text { Tekanan } \\
\text { Darah pada } & \text { Lansia } \\
\text { Hipertensi } & \end{array}$ & $\begin{array}{l}\text { Metode yang digunakan } \\
\text { Quasi experimental pre-post } \\
\text { test. ampel dalam } \\
\text { penelitian ini adalah lansia } \\
\text { di Kelurahan Dadok Tunggul } \\
\text { Hitam, yang berjumlah } 32 \\
\text { responden, } 16 \text { untuk } \\
\text { kelompok kontrol dan } 16 \\
\text { untuk kelompok intervensi. } \\
\text { Analisis data yang digunakan } \\
\text { adalah Univariat dan } \\
\text { Bivariat menggunakan } \\
\text { Independent t test. }\end{array}$ & $\begin{array}{l}\text { Pada kelompok intervensi } \\
\text { sebelum dilakukan senam } \\
\text { didapatkan nilai rata-rata } \\
\text { tekanan darah adalah } 180,5 \\
\text { mmHg dan sesudah senam } \\
\text { sebanyak } 130 \mathrm{mmHg} \text {. Pada } \\
\text { kelompok kontrol sebelum } \\
\text { dilakukan senam didapatkan } \\
\text { nilai rata-rata tekanan } \\
\text { darah adalah } 176 \text { mmHg dan } \\
\text { sesudah senam sebesar } 150 \\
\text { mmHg. Berdasarkan uji } \\
\text { statistik terdapat pengaruh } \\
\text { senam lansia Jterhadap } \\
\text { tekanan darah pada Lansia } \\
\text { Hipertensi dengan nilai } \mathrm{p}= \\
0,001 \text {. }\end{array}$ & $\begin{array}{l}\text { Google } \\
\text { Cendikia }\end{array}$ \\
\hline 17 & $\begin{array}{l}\text { Dachi, F., } \\
\text { dkk }\end{array}$ & 2021 & $\begin{array}{lr}\text { Pengaruh } & \text { Senam } \\
\text { Lansia } & \text { Terhadap } \\
\text { Perubahan } & \text { Tekanan } \\
\text { Darah } & \\
\text { Pada } & \text { Penderita } \\
\text { Hipertensi } & \end{array}$ & $\begin{array}{l}\text { Metode penelitian ini adalah } \\
\text { mengunakan metode Pre- } \\
\text { eksperimen desain dengan } \\
\text { mengunakan rancangan One } \\
\text { Group Pretest-posttest. } \\
\text { Sampel } 20 \text { responden } \\
\text { dengan menggunakan teknik } \\
\text { Purposive Sampling. Data } \\
\text { yang diolah mengunakan uji } \\
\text { statistik T-Test. }\end{array}$ & $\begin{array}{l}\text { Ada Pengaruh Senam Lansia } \\
\text { terhadap Perubahan } \\
\text { Tekanan Darah pada } \\
\text { Penderita Hipertensi di } \\
\text { buktikand dengan p value } \\
\text { sebesar } 0,001<0,05 \text {. }\end{array}$ & $\begin{array}{l}\text { Google } \\
\text { Cendikia }\end{array}$ \\
\hline 18 & $\begin{array}{c}\text { Kardi, I. S., } \\
\text { dkk }\end{array}$ & 2019 & $\begin{array}{l}\text { Pengendalian } \\
\text { Tekanan Darah Tinggi } \\
\text { Masyarakat RW } 12 \\
\text { Jebres Melalui Senam } \\
\text { Aerobik }\end{array}$ & $\begin{array}{lr}\text { Desain } & \text { penelitian } \\
\text { menggunakan pre test-post } \\
\text { test dengan Sampel } 27 \\
\text { orang. Uji analisa } \\
\text { menggunakan persentase } \\
\text { sebelum dan setelah diukur } \\
\text { tekanan darahnya } \\
\end{array}$ & $\begin{array}{l}\text { Hasil pemeriksaan tekanan } \\
\text { darah yang diperoleh } \\
\text { sebanyak } 43 \text { orang }(61,43 \%) \\
\text { memiliki tekanan darah } \\
\text { normal dan } 27 \text { orang } \\
(38,57 \%) \text { memiliki tekanan } \\
\text { darah tinggi. }\end{array}$ & $\begin{array}{l}\text { Google } \\
\text { Cendikia }\end{array}$ \\
\hline 19 & $\begin{array}{l}\text { Ekarini, N. } \\
\text { L. P., dkk }\end{array}$ & 2019 & $\begin{array}{lr}\text { Pengaruh } & \text { Terapi } \\
\text { Relaksasi } & \text { Otot } \\
\text { Progresif } & \text { terhadap } \\
\text { Respon } & \text { Fisiologis } \\
\text { Pasien Hipertensi }\end{array}$ & 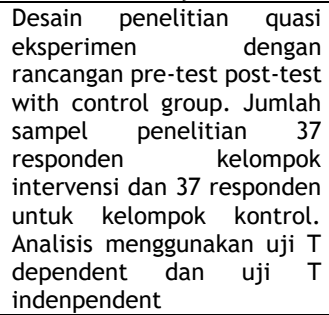 & $\begin{array}{lr}\text { Hasil } & \text { penelitian } \\
\text { menunjukkan } & \text { bahwa } \\
\text { terdapat darah diastolik } \\
\text { tekanan darah } \\
\text { antara kelompok intervensi } \\
\text { dan kelompok kontrol } \\
\text { setelah dilakukan intervensi } \\
\text { relaksasi otot progresif } \\
(p=0,000) \text {. }\end{array}$ & $\begin{array}{l}\text { Google } \\
\text { Cendikia }\end{array}$ \\
\hline
\end{tabular}




\section{PEMBAHASAN}

Latihan Fisik dalam Menurunkan Tekanan Darah Pasien Hipertensi

Latihan fisik yang teratur dapat bermanfaat bagi fisiologis tubuh yaitu mengatur kadar gula darah, merangsang adrenlin dan noradrenalin, peningkatan kualitas dan kuantitas tidur, dapat menurunkan tekanan darah/ kardiovaskuler, kekuatan otot rangka, kelenturan dan kelincahan gerak (Saputra \& Daud, 2020).

Latihan fisik dalam paparan jurnal yang didapatkan terdiri atas: senam aerobik, walking (berjalan), latihan kardio, senam lansia, olahraga, home-base exercise training, dan latihan resistensi isometrik.

\section{Senam aerobik}

Berdasarkan penelitian, latihan aerobik sedang dapat dilakukan sehari-hari selama 30 menit agar dapat menurunkan tekanan darah (Saputra \& Daud, 2020). Hal ini sedikit berdeda dengan penelitian Kardi., dkk (2019) dimana frekuensi latihannya 3-5 kali seminggu dengan lama latihan 20-60 menit setiap latihan. Latihan olahraga bisa menurunkan tekanan darah karena latihan itu dapat merilekskan pembuluh-pembuluh darah. Sehingga berolahraga yang bersifat aerobik secara rutin dapat menurunkan risiko penyakit jantung koroner melalui mekanisme penurunan denyut jantung dan tekanan darah, penurunan tonus simpatik, meningkatkan diameter arteri koroner dan sistem kolateralisasi pembuluh darah, meningkatkan HDL dan menurunkan LDL darah.
Walking (berjalan)

Dalam penelitian Arija., et al (2018) latihan fisik yang dilakukan berupa walking atau berjalan dimana latihan ini dilakukan selama 9 bulan, latihan walking ini dibuat dalam kelompok-kelompok yang dilakukan selama 120 menit/minggu sejauh 396 meter dalam 2 sesi selama 60 menit yang dipantau oleh seorang perawat dan seorang fisioterapi.

Didukung oleh penelitian Zang., et al (2020) bahwa olahraga dan perilaku yang berhubungan dengan olahraga seperti berjalan selama 60-120 menit/hari waktu olahraga menjadi faktor utama untuk mengontrol tekanan darah pada pasien hipertensi.

Latihan kardiovaskular

Pada dasarnya, setiap latihan fisik dapat berpengaruh dalam sirkulasi sistem kardiovaskular dimana hal ini terbukti menjadi prediktor kuat untuk penyakit hipertensi, setiap latihan dapat dimodifikasi tergantung pada efek yang ingin didapatkan dari latihan tersebut. Berbagai jenis latihan fisik harus ditentukan sebelum dilakukan karena tujuannya dari latihan utamanya untuk pencegahan, pengobatan, dan pengendalian hipertensi. Latihan fisik dapat dilakukan baik pada intensitas terus menerus atau dengan interval pendek dengan latihan intensitas rendah, sedang dan tinggi (Arija., et al).

Menurut Rahmawati., dkk (2019) intervensi yang dilakukan pada latihan kardio dapat dilakukan dengan berjalan kaki, durasi kurang lebih 30 menit, yang diawali dengan 
pemanasan selama 5 menit dan diakhiri pendinginan selama 5 menit, frekuensi 2 kali seminggu selama satu bulan. Sebelum latihan kardio sebaiknya mengukur tekanan darah sebelum dan setelah melakukan intervensi.

\section{Senam Lansia}

Jenis latihan fisik yang bisa di lakukan antara lain adalah senam lansia. Senam lansia adalah serangkaian gerak nada yang teratur dan terearah serta terencana yang diikuti oleh orang lanjut usia dalam bentuk latihan fisik yang berpengaruh terhadap kemampuan fisik lansia. Aktifitas olahraga ini akan membantu tubuh agar tetap bugar dan tetap segar karena melatih tulang tetap kuat dan membantu menghilangkan radikal bebas yang berkeliaran dalam tubuh (Saputra \& Daud, 2020).

Penelitian yang dilakukan oleh Sianipar \& Putri (2018) terkait senam lansia dilakukan selama 3 minggu dengan frekuensi senam 2 kali dalam seminggu. Sedangkan penelitian Dachi., dkk (2021) senam lansia dilakukan dengan intensitas sedang, serta frekuensi latihan 3-5 kali seminggu dengan lama latihan 20-60 menit sekali latihan.

Olah raga teratur

Latihan fisik yang dilakukan otot dengan terencana dan berulang dapat meningkatkan pemakaian energi dengan tujuan memperbaiki kebugaran fisik yang dilakukan minimal 30 menit olahraga sedang untuk kesehatan jantung, 60 menit untuk mencegah kenaikan berat badan dan 90 menit untuk menurunkan berat badan. Melakukan olahraga secara teratur dapat menjaga bentuk dan berat badan dan juga dapat menurunkan tekanan darah (Saputra \& Daud, 2020).

Sedikit berbeda dengan penelitian Zang., et al (2020) yang menunjukkan korelasi antara waktu olahraga sebaiknya 60-120 menit/hari dan tekanan darah kontrol, selain itu frekuensi latihan dan durasi latihan bukanlah faktor independen untuk mengontrol tekanan darah.

Home-base exercise training

Home-based exercise training dapat menjadi salah satu pilihan latihan fisik dan alternatif solusi rendahnya partisipasi pasien mengikuti latihan fisik. Home-based exercaise training merupakan latihan fisik terprogram yang dapat dijalankan oleh pasien secara mandiri di rumah. Metode ini menawarkan beberapa keuntungan dibandingkan latihan fisik yang dilakukan terpusat di rumah sakit diantaranya memberikan kesempatan pada pasien, mempunyai waktu lebih banyak untuk keluarga dan menurunkan biaya. Home-based exercaise training dapat dilakukan berupa jalan kaki, bersepeda, tipe latihan fisik ini efektif bagi pasien hipertensi latihan ini bersifat dinamis dan tahanan ringan. Latihan ini dilakukan dengan durasi 30 menit selama 2 minggu, frekuensi 3 kali dalam 1 minggu (Rida, 2019).

Menurut penelitian Babu., et al (2019) efek dari home-base exercise training yang dilakukan selama 12 minggu dapat meningkatkan kapasitas fungsional tubuh. Kapasitas fungsional ini dinilai menggunakan: jalan kaki 6 menit uji 
sesuai dengan rekomendasi standar, sebanyak 84 peserta terdaftar dalam latihan ini, 67 di antaranya menyelesaikan intervensi pelatihan latihan berbasis rumah selama 12 minggu.

\section{Latihan resistensi isometrik (handgrip)}

Menurut Ivan., et al (2016) latihan isometrik menunjukkan penurunan tekanan darah sistolik dan diastolik yang lebih besar, masing-masing 10,9 dan 6,2 mmHg, dibandingkan dengan jenis latihan lainnya, dimana latihan isometrik ini lebih efisien dalam pengurangan hipertensi pada pria berusia $>45$ tahun, dengan cara menggunakan latihan lengan secara individu selama minimal 8 minggu pelatihan. Durasi $4 \times 2$ menit (istirahat 1-4 menit) dari $20-50 \%$ kontraksi volunter maksimal, 3-4 hari/minggu selama minimal 4-10 minggu, latihan dilakukan pada ekstremitas bawah (leg press atau jongkok) atau ekstremitas atas (handgrip).

Sedangkan menurut Choirillaily \& Ratnawati (2020) latihan isometrik pada otot tidak menunjukkan adanya perubahan pada tekanan darah yang signifikan, namun khusus latihan pada bagian handgrip menunjukkan terjadi penurunan tekanan darah. Sehingga perlu dipertimbangkan kembali latihan isometrik dari berbagai publikasi walau masih relatif sedikit.

Hal ini didukung oleh penelitian Susiladewi., dkk (2017) pengaruh latihan isometrik terhadap tekanan darah pasien hipertensi, berdasarkan uji-t sampel independen, perbedaan ini signifikan secara statistik dengan tingkat signifikansi $p=0,000 \quad(a<0,05)$, perbedaan ini terlihat dari menurunnya tekanan darah sistol dan diastol selama perlakukan diberikan.

\section{Prosedur Latihan Fisik}

Beberapa aspek yang harus diperhatikan sehubungan dengan latihan fisik pada orang yang terkena hipertensi adalah: (1) Kemajuan harus bertahap, menghindari peningkatan besar, terutama dalam variabel intensitas, (2) Jangan memulai program latihan jika orang tersebut menunjukkan nilai tekanan arteri $180 / 105 \mathrm{mmHg}$ atau lebih tinggi, (3) Pantau tekanan darah selama (atau di akhir set) latihan dengan rata-rata dua pengukuran berturut-turut dengan jarak 30 detik, (4) Gunakan fase pendinginan minimal 5-10 menit, untuk menghindari efek hipotensi pascalatihan yang berlebihan, (5) Jika respons terhadap olahraga adalah hipotensi, yaitu ketidakmampuan untuk meningkatkan tekanan darah meskipun tuntutan untuk latihan fisik meningkat, biasanya kurang dari $20-30 \mathrm{mmHg}$, olahraga harus dihentikan, (6)

Berikan waktu pemulihan yang cukup, setidaknya 30 detik, untuk kembali ke kondisi dasar sistem kardiovaskular, (7) Hindari latihan yang membuat tingkat kepala berada di bawah pinggul (latihan menurun), (8) Hindari jumlah pengulangan latihan yang berintensitas tinggi dan beresiko mengalami kegagalan otot dalam latihan, dan (9) Perlu dipertimbangkan juga faktor resiko lain yang berhubungan dengan usia, jenis kelamin, dan penyakit 
penyerta, sebelum melakukan latihan fisik yang berat.

\section{KESIMPULAN}

Dari hasil pembahasan dapat ditarik kesimpulan bahwa hipertensi merupakan salah satu faktor risiko yang paling penting dalam kejadian penyakit hipertensi, latihan aerobik dan latihan resistensi memperbaiki kesehatan secara umum dan dapat memperbaiki faktor risiko kardiovaskular, termasuk memiliki efek menurunkan tekanan darah dan mengurangi kejadian mortalitas. Perbandingan efek kesehatan antara latihan aerobik dan latihan resistensi isometrik belum memiliki penjelasan yang tepat pada pasien hipertensi, akan tetapi jika tujuan utama latihan adalah menurunkan tekanan darah, maka latihan yang direkomendasikan adalah latihan aerobik. Latihan aerobik secara universal direkomendasikan sebagai terapi inisial gaya hidup untuk individu dengan hipertensi karena dapat menurunkan tekanan darah 5$7 \mathrm{mmHg}$ pada penderita hipertensi.

\section{DAFTAR PUSTAKA}

Adamas, M. (2019). Pengaruh latihan fisik aerobik terhadap tekanan darah pasien hipertensi di RS Pertamedika Pertamina Plaju Palembang (Doctoral dissertation, Universitas Muhammadiyah Palembang).

Arija, V., Villalobos, F., Pedret, R., Vinuesa, A., Jovani, D., Pascual, G., \& Basora, J. (2018). Physical activity, cardiovascular health, quality of life and blood pressure control in hypertensive subjects: randomized clinical trial. Health and quality of life outcomes, 16(1), 184. https://doi.org/10.1186/s12 955-018-1008-6

Babu, A. S., Padmakumar, R., Nayak, K., Shetty, R., Mohapatra, A. K., \& Maiya, A. G. (2019). Effects of home-based exercise training on functional outcomes and quality of life in patients with pulmonary hypertension: A randomized clinical trial. Indian heart journal, 71(2), 161-165. https://doi.org/10.1016/j.i hj.2019.03.002

Diaz, K. M., Booth, J. N., 3rd, Seals, S. R., Abdalla, M., Dubbert, P. M., Sims, M., Ladapo, J. A., Redmond, N., Muntner, P., \& Shimbo, D. (2017). Physical Activity and Incident Hypertension in African Americans: The Jackson Heart Study. Hypertension (Dallas, Tex.: 1979), 69(3), 421-427.

https://doi.org/10.1161/HY PERTENSIONAHA. 116.08398

Hernawan, T., \& Rosyid, F. N. (2017). Pengaruh senam hipertensi lansia terhadap penurunan tekanan darah lansia dengan hipertensi di Panti Wreda Darma Bhakti Kelurahan Surakarta. Jurnal Kesehatan, 10(1), 26-31.

Iván, C. M. (2016). José, S. C., Juan, T. M., and Manuel, C. T. J (2016). Exercise for Hypertension, Fitness Medicine, Hasan Sozen, IntechOpen, DOI: 10.5772/65035. Available from:

https://www.intechopen.co $\mathrm{m} /$ chapters $/ 52252$.

Izhar, D. (2017). Pengaruh senam lansia terhadap tekanan darah di Panti Sosial Tresna Werdha Budi Luhur Jambi. Jurnal Ilmiah Universitas 
Batanghari Jambi, Vol.17 No.1 Tahun 2017.

Larasiska, A., \& HN, W. P. (2017). Menurunkan tekanan darah dengan cara mudah pada lansia. IJNP (Indonesian Journal of Nursing Practices), 1(2), 55-63.

Nascimento, L. S., Santos, A. C., Lucena, J., Silva, L., Almeida, A., \& BrasileiroSantos, M. S. (2017). Acute and chronic effects of aerobic exercise on blood pressure in resistant hypertension: study protocol for a randomized controlled trial. Trials, 18(1), 250. https://doi.org/10.1186/s13 063-017-1985-5

Pedralli, M. L., Marschner, R. A., Kollet, D. P., Neto, S. G., Eibel, B., Tanaka, H., \& Lehnen, A. M. (2020). Different exercise training modalities produce similar endothelial function improvements in individuals with prehypertension or hypertension: a randomized clinical trial Exercise, endothelium and blood pressure. Scientific reports, 10(1), 7628. https: / / doi.org/10.1038/s41 598-020-64365-x.

Rahmawati, A., Mardiyani, R., \& Amrullah, S. (2019). Efektivitas home based exercise walking terhadap tekanan darah pasien dengan congestive heart failure. Jurnal Keperawatan dan Kesehatan, 10(1), 8-13.

Rahmiati, C., \& Zurijah, T. I. (2020). Pengaruh Senam Lansia Terhadap Tekanan Darah Pada Lansia Dengan Hipertensi. Jurnal Penjaskesrek, 7(1), 15-27.

Ratnawati, D., \& Choirillaily, S. (2020). Latihan
Menggenggam Alat Handgrip Menurunkan Tekanan Darah

Pada Penderita

Hipertensi. Jurnal

Keterapian Fisik, 5(2), 101 108.

Rida, Z. (2019). Pengaruh Home Based Exercise Training Terhadap Penurunan Tekanan Darah Pada Hipertensi Lansia (Di Desa Pandanwangi Kecamatan Diwek Jombang) (Doctoral dissertation, STIKes Insan Cendekia Medika Jombang).

Riset Kesehatan Dasar. (2018). Badan Penelitian dan Pengembangan Kesehatan Kementerian RI tahun 2018.

Saputra, F. S., \& Daud, T. (2020). Pengaruh latihan fisik terhadap penurunan hipertensi pada lansia di Poswindu Wilayah Kerja Puskesmas Bintuhan Kabupaten Kaur Tahun 2019. Journal of Nursing and Public Health, 8(1), 29-36.

Sarastuti, A. W., \& Widyantoro, B. (2018). Latihan Fisik bagi Penderita

Hipertensi. Cermin Dunia Kedokteran, 45(12), 930 933.

Sumartini, Zulkifli \& Adhitya. (2019). Pengaruh senam hipertensi lansia terhadap tekanan darah lansia dengan hipertensi di Wilayah Kerja Puskesmas Cakranegara kelurahan Turida tahun 2019. Jurnal Keperawatan Terpadu.

Susiladewi, I. A. M. V., Widyanthari, D. M., \& Adnyana, I. M. O. (2017). Pengaruh latihan isometrik terhadap tekanan darah pasien hipertensi. Coping

Community Publ Nurs, 5, 153-160.

World Health Organization. (2018). 
Physical Activity. Diakses 16

Juni 2021 dari

http://www.who.int/news-

room/fact-

sheets/detail/physical-

activity.

Zhang, C., Zhang, Y., Lin, H., Liu, S., Xie, J., Tang, Y., Huang, H., \& Zhang, W. (2020). Blood pressure control in hypertensive patients and its relation with exercise and exercise-related behaviors: A case-control study. Medicine, 99(8), e19269.

https://doi.org/10.1097/MD .0000000000019269 